\title{
PABLO GUERRA
}

Doctor en Ciencias Humanas. Profesor e Investigador, Instituto de Sociología Jurídica, Facultad de Derecho, Universidad de la República (Uruguay). Investigador Activo del Sistema Nacional de Investigadores. pablo.guerra@fder.edu.uy

Orcid ID: https://orcid.org/0000-0002-2586-7|75

ROMINA GALLARDO Doctora en Derecho y Ciencias Sociales por la Universidad de la República (Uruguay). rmgd26@gmail.com Orcid ID: https://orcid.org/0000-0003-2909-9190 Recibido: 08/06/2021 - Aceptado: 10/1 1/2021

\section{Proxenetismo en Uruguay. Análisis de sentencias judiciales en aplicación de la Ley 8080}

Resumen: En este artículo se analizan las características del delito de proxenetismo a partir de las sentencias judiciales definitivas que en aplicación de la Ley 8080 y sus posteriores modificaciones, tuvieron lugar en el período 2000 - 2020, tomando como fuente de información la Base de Jurisprudencia Nacional del Poder Judicial.

La información se ordena mediante cuadros resúmenes relevando las siguientes variables: Juzgado; Número de Resolución y Año; Delitos; Número de personas procesadas; tipo de prostitución afectado; leyes penales aplicadas; resumen de la sentencia y del caso.

A partir de la información recabada se establecen algunas tipologías del delito y se comenta las complejidades del tipo "proxenetismo velado" muy usual entre propietarios de prostíbulos.

Palabras Clave: Prostitución; Proxenetismo; Ley 8080; Jurisprudencia; Uruguay 


\title{
Pimping crime in Uruguay. Judicial rulings in application of Law 8080
}

\begin{abstract}
This article analyzes the characteristics of the crime of pimping based on the judicial decisions that, in application of Law 8080 and its subsequent modifications, took place in the period 2000 - 2020, taking as a source of information the National Jurisprudence Base of Judicial Power. The information is arranged by summary tables, revealing the following variables: Court; Resolution Number and Year; Crimes; Number of persons processed; type of prostitution affected; applied criminal laws; summary of the rulling and the case.
\end{abstract}

Based on the information collected, some typologies of the crime are established. Particularly, we discussed the complexities of the type "veiled pimping" very common among brothel owners.

Keywords: Prostitution; Procuring; 8080 Law; Jurisprudence; Uruguay

\section{Lenocínio no Uruguai. Análise de sentenças judiciais na aplicação da Lei 8.080}

Resumo: Neste artigo analisam-se as características do crime de lenocínio com base nas decisões judiciais definitivas que, em aplicação da Lei 8.080 e suas posteriores modificações, ocorreram no período de 2000-2020, tomando como fonte de informação a Base Nacional de Jurisprudência do Poder Judicial.

As informações são organizadas por meio de tabelas resumo, considerando as seguintes variáveis: Tribunal; Número e ano da resolução; Crimes; Número de pessoas processadas; tipo de prostituição afetada; leis criminais aplicadas; resumo da sentença e do caso. A partir das informações coletadas, são estabelecidas algumas tipologias do crime e discutidas as complexidades do tipo "lenocínio velado", muito comum entre donos de bordéis.

Palavras-Chave: Prostituição; Lenocínio; Lei 8080; Jurisprudência; Uruguai 


\section{Sobre el delito de proxenetismo en Uruguay}

Respecto a la legislación nacional, el proxenetismo como delito está presente en el Código Penal Uruguayo, Título X, De los delitos contra las buenas costumbres y el orden de la familia, Cap. IV, De la violencia carnal, corrupción de menores, ultraje público al poder y su Art. 274 ("corrupción") haciéndose referencia en el inciso tercero que "comete delito de proxenetismo y se halla sujeto a las penas respectivas el que ejecutare algunos de los hechos previstos por la ley especial del 27 de Mayo de 1927" (Código Penal, 2019).

Efectivamente, el Código Penal hace referencia a la Ley 8080, a la que se llega luego de haberse tipificado antes en el Código Penal de 1889 y en la Ley 5520 del 20 de Octubre de 1916.

La vigente Ley $8080^{1}$ del 27 de Mayo de 1927 con su posterior Reglamentación que tanto lamentarían las corrientes abolicionistas ${ }^{2}$ está organizada en 21 artículos. Los dos primeros artículos definen y penalizan el delito:

“Artículo $\mathbf{1}^{\circ}$.- Toda persona de uno u otro sexo, que explote la prostitución de otra contribuyendo a ello en cualquier forma con ánimo de lucro, aunque haya mediado el consentimiento de la víctima, será castigada con dos a ocho años de penitenciaría. En caso de reincidencia las agravantes se aplicarán sobre el máximum de la pena legal.

Artículo $2^{\circ}$.- La pena mínima será de cuatro años de penitenciaría, si la víctima fuera menor de catorce años o el delincuente fuere funcionario policial o el hecho se produjere mediante engaño, violencia, amenaza de un mal grave, abuso de autoridad u otro medio de intimidación o coacción, como también si el actor fuera ascendiente, marido, hermano, tutor o encargado de la guarda de la víctima o hiciera vida marital con ella" (Ley 8080, 1927).

La redacción del primer artículo es de cuño abolicionista hasta el punto de haber participado en la misma, la Dra. Paulina Luisi. Es que en su momento existió mucha expectativa del espectro abolicionista con respecto a esta Ley, incluso con la esperanza de erradicar las "casas de tolerancia" tan vigentes en la legislación anterior junto a la figura de los regentes autorizados.

Más tarde, la Ley 16.707 (Ley de Seguridad Ciudadana de 1995) en su Art. 24 modifica la redacción original, disponiendo lo siguiente:

“Art. 24.- Sustitúyense los artículos $1^{\circ}$ y $2^{\circ}$ de la Ley No 8.080, de 27 de mayo de 1927, por los siguientes:

"ARTICULO $1^{\circ}$ - Toda persona de uno u otro sexo, que explote la prostitución de otra contribuyendo a ello en cualquier forma con ánimo de lucro, aunque haya mediado el consentimiento de la víctima, será castigada con dos a ocho años de penitenciaría. En caso de reincidencia las agravantes se aplicarán sobre el máximo de pena legal.

1 Su vigencia opera con las modificaciones dadas por la Ley 16707 de 1995.

2 Comentaría en tal sentido la Dra. Paulina Luisi sobre el Decreto Reglamentario "La prostitución reglamentada, con el prostíbulo abierto como un honesto negocio, es la escuela más funesta para la moralidad, es el agente más poderoso y enérgico para la corrupción y la pornografía en gran escala / .../ puesto que ella significa la aprobación legal y el beneplácito social de su existencia" (Guerra, 2006, p.18). 
El que, con ánimo de lucro, indujere o determinare a otro al ejercicio de la prostitución, en el país o en el extranjero, será castigado con tres a doce meses de prisión"3.

“ARTICULO 20 - La pena mínima será de cuatro años de penitenciaría si la víctima fuere menor de dieciocho años o el delincuente fuere funcionario policial o el hecho se produjere mediante engaño, violencia, amenaza de un mal grave, abuso de autoridad u otro medio de intimidación o coacción, como también si el actor fuera ascendiente, marido, hermano, tutor o encargado de la guarda de la víctima o hiciera vida marital con ella" (Ley 16707, 1995).

Como se observa, el legislador pretendió mediante la modificación, actualizar la norma contemplando el fenómeno de la trata de personas. También fue necesario establecer un criterio más acorde respecto a la temática de los derechos de niños, niñas y adolescentes, razón por la cuál el límite de edad del agravante se lleva de los 14 a los 18 años de edad. Corresponde señalar que el primer párrafo del Art. 1 no sufre modificación.

Siguiendo a Fleitas, tenemos en este Art. 1 que el proxenetismo asume dos modalidades, esto es, el proxenetismo sensu stricto y el proxenetismo en tanto inducción o determinación a la prostitución, o lo que es lo mismo el "delito de reclutamiento" que daría lugar luego a un delito autónomo bajo la fórmula de Trata de Personas (Fleitas, 2014: 69).

Así entonces, el proxenetismo stricto sensu consiste en "explotar la prostitución" contribuyendo a ello "de cualquier forma" y "con ánimo de lucro". Respecto al giro verbal "contribuyendo a ello de cualquier forma" (aplicado a la "explotación") el legislador procuró eliminar enumeraciones casuísticas que pudieran ser incompletas de manera de abarcar todos los casos posibles de proxenetismo ${ }^{4}$. Respecto al "ánimo de lucro" es herencia del Código Alemán de 1900 y como señalaban Irureta Goyena y Abadie Santos, no era una condición exigida en otros Códigos, caso del Austríaco o del Brasilero de la época (Abadie Santos, 1932, p. 56). A nuestro entender, el legislador intentó posicionar la idea que obtener una ganancia o asociarse a una ganancia por medio de la prostitución de otro, es ilícito. La presencia de ánimo de lucro es relevante, en tanto dejaría fuera a la figura del rufián "que se deja sostener por la prostituta, pero sin contribuir en modo alguno a ello, porque es la supuesta víctima la que voluntariamente le entrega el producto de sus ganancias" (Fleitas, 2014, p. 69) así como otras motivaciones, caso del móvil vengativo.

Más allá del espíritu de los legisladores de la época respecto a no tolerar ningún tipo posible de proxenetismo, con el paso del tiempo el eje se fue poniendo en la interpretación que se le podía dar al verbo "explotar"5. En tal sentido, fue predominando la idea que explotaba quien se beneficiaba de forma abusiva, de tal manera que recae en el Juez la potestad de definir el baremo que distingue entre un lucro no abusivo y otro abusivo y por lo tanto pasible de ser penado ${ }^{6}$.

3 En nuestra opinión el delito de reclutamiento habría sido derogado por la ley No 18.250 y ley 19643 que tipificó los delitos migratorios y dentro de ellos, el de tráfico de personas y trata de personas.

4 Eso se desprende del Informe de la Comisión del Senado con fecha 16 de Mayo de 1927, Ver Abadie Santos (1932, p. 72).

5 Un análisis más exhaustivo sobre las diferentes lecturas que pueden hacerse del verbo "explotar" con relación al delito de proxenetismo puede verse en Guerra (2016).

6 Para mayor complejidad, no se trata de dirimir el asunto desde un punto de vista cuantitativo. Dice Cairoli que el ánimo de lucro "no se rige ni se evalúa por la magnitud o cantidad de ganancia del agente, sino simplemente por su intención de obtener cualquier ganancia, aunque esta no sea muy grande..." (Cairoli, 1989, p. 297). 
En cuanto a la figura del "reclutamiento", ya no se espera que el sujeto contribuya a la explotación, sino que bastaría con inducir o determinar a la víctima a ejercer el meretricio con fines de lucro (o sea, obteniendo una ganancia).

Finalmente, la norma establece una serie de agravantes, a saber: edad de la víctima (menores de 18 años), si el agente fuera funcionario policial, si hubiere relación parental o si mediare engaño o medios violentos.

Respecto a la legislación conexa, debemos citar las siguientes:

\section{(a) Ley 17515 sobre Trabajo Sexual.}

Nuestro país se incorpora a la lista de países que adoptan el modelo regulacionista a partir de la aprobación de la Ley 17515 del 2002. Esta Ley considera lícito el trabajo sexual a partir de los 18 años de edad, siempre que se realice de acuerdo a las condiciones establecidas. Así entonces, el art. $2^{\circ}$ inc. $1^{\circ}$ considera como trabajadores sexuales a

"todas las personas mayores de dieciocho años de edad que habitualmente ejerzan la prostitución, recibiendo a cambio una remuneración en dinero o en especie" (Ley $17515,2002)$.

Además de este requisito de edad se exige la habitualidad en el ejercicio de la prostitución a cambio de una retribución, es decir, que se trata de una actividad onerosa.

El inciso $2^{\circ}$ exige que los trabajadores sexuales: a) se inscriban en un Registro Nacional del Trabajo Sexual; y b) poseer el carné sanitario con los controles al día. A efectos de controlar el trabajo sexual la ley crea una Comisión Nacional Honoraria de Protección al Trabajo Sexual en la órbita del Ministerio de Salud Pública (arts. $5^{\circ}$ y $6^{\circ}$ ). Nótese cómo estos artículos colocan al modelo uruguayo como regulacionista: a diferencia del modelo laboralista, los controles establecidos en la Ley uruguaya no forman parte del Ministerio del Trabajo, sino del Ministerio del Interior y Ministerio de Salud Pública.

Es de destacar entonces, que la ley comentada reglamenta a la prostitución como una actividad autónoma e independiente, en que el prestador de servicios sexuales debe inscribirse motu proprio en un Registro de carácter personal y contar con los controles clínicos necesarios para ejercer su oficio. Por lo demás, en un hecho trascendente para nuestro propósito, y a su vez de larga data en la discusión pública, establece la presunción de delito de proxenetismo para aquellos terceros que exploten algún local para el ejercicio del trabajo sexual (léase prostíbulo, whiskería o casas de masajes). Dice el Art. 34:

"Según las circunstancias del caso, podrá presumirse incursa en el delito previsto por el artículo $1^{\circ}$ de la Ley $\mathrm{N}^{\circ} 8.080$, de 27 de mayo de 1927, en la redacción dada por el artículo 24 de la Ley $\mathrm{N}^{\circ}$ 16.707, de 12 de julio de 1995, toda persona que explotare una finca para el ejercicio del trabajo sexual, percibiendo por esto un precio que le provea a ella o a un tercero un beneficio excesivo" (Ley 17515, 2002).

Como se dijo antes, se deja a criterio del Juez determinar qué sería un beneficio excesivo, aspecto que como se comprenderá resulta de fundamental importancia en el marco de nuestro análisis sobre la Jurisprudencia. 
(b)Ley 17815 sobre Violencia Sexual comercial o no comercial contra Niños, Adolescentes o Incapaces

Esta Ley del 2004 establece penas para diversos tipos de delitos sexuales contra niños, niñas, adolescentes e incapaces. Incluye en el Art. 5 el delito de Contribución a la explotación sexual de personas menores de edad o incapaces.

“El que de cualquier modo contribuyere a la prostitución, explotación, o servidumbre sexual de personas menores de edad o incapaces, será castigado con pena de dos a doce años de penitenciaría.

La pena será elevada de un tercio a la mitad si se produjere con abuso de las relaciones domésticas o de la autoridad o jerarquía, pública o privada, o la condición de funcionario policial del agente" (Ley 17815, 2004).

(c) La ley 18250 sobre Migraciones (2008) introduce la trata como tipo penal autónomo, estableciendo un castigo con penas de entre cuatro y diez y seis años de prisión a quien

de cualquier manera, o por cualquier medio participare en el reclutamiento, transporte, transferencia, acogida o el recibo de personas para el trabajo o servicios forzados, la esclavitud o prácticas similares, la servidumbre, la explotación sexual, la remoción y extracción de órganos (...) (Ley 18250, 2008).

(b)Ley 19463 sobre Prevención y Combate de la Trata de Personas

Se trata de una Ley con un tratamiento más integral del fenómeno de la Trata de Personas. El Art. 4 define a la Trata como

La captación, el reclutamiento, el transporte, el traslado, la acogida, la recepción o el hospedaje de personas, dentro del territorio nacional o a través de fronteras, aunque mediare el consentimiento de las mismas, con fines de explotación. Sin perjuicio de otras formas de explotación, se consideran tales la explotación sexual, el matrimonio forzado o servil, el embarazo forzado, los trabajos o servicios forzosos u obligatorios, la esclavitud o las prácticas análogas a la esclavitud, la servidumbre, la explotación laboral, la mendicidad forzada, la extracción o transferencia ilícita de órganos, tejidos o fluidos humanos y la venta de personas, especialmente de niños, niñas o adolescentes (Ley 19463, 2018).

Una de las expresiones más importantes de esta definición, al igual que en la Ley 8080, es "explotación" definida en este caso por el literal E del Art. 4 como

La obtención de un beneficio, económico o de otro tipo, para el explotador o para terceros, mediante la participación o el sometimiento de una o más personas a cualquier tipo de acto o estado que lesione o anule sus derechos humanos (Ley 19463, 2018). 
Teniendo en cuenta este conjunto de leyes, asoma como propósito de este artículo analizar el tratamiento recibido por parte del Poder Judicial respecto al delito del proxenetismo. Algunas de las preguntas que intentaremos responder en este artículo son: ¿Es el delito de proxenetismo actualmente perseguido? ¿En qué circunstancias se aplica la Ley 8080? ¿La regulación de la prostitución como trabajo afecta la persecución del proxeneta? ¿Se observa en la Jurisprudencia conexiones con otros delitos caso de trata de personas o explotación sexual comercial de niños/as y adolescentes?

\section{Metodología}

Análisis descriptivo y crítico sobre la aplicación de la Ley 8080 y la represión del proxenetismo a partir de los casos judiciales que han dado lugar a sentencias definitivas en materia penal para el período 2000 - 2020.

Para este estudio se consultó la Base de Jurisprudencia Nacional del Poder Judicial de Uruguay (BJN). De allí se obtuvieron 26 Sentencias Penales Definitivas: 25 Sentencias de Segunda Instancia y 1 Sentencia de Recurso de Casación.

Los términos de búsqueda fueron mediante las palabras "8080" y "proxenetismo". También se aplicó técnica de bola de nieve a partir de los casos publicados en la citada Base. Es así que se logró acceso a otras tres sentencias para el período de referencia, aunque solamente dos de ellas era de carácter definitivo, por lo que en total se analizan 28 sentencias definitivas para el período.

Ordenamiento de la Información: se establecerán cuadros resúmenes con la siguiente información, a saber: Juzgado; Número de Resolución y Año; Delitos; Número de personas procesadas; tipo de prostitución afectado; leyes penales aplicadas; resumen de la sentencia y del caso.

\section{Notas Metodológicas:}

En la Base están cargadas las sentencias dictadas por la Suprema Corte de Justicia a partir del año 1989 y las de Tribunales de Apelaciones desde el año 2005. Las sentencias de Primera Instancia se comenzaron a subir recién en el año 2020, lo impacta en la calidad de la muestra.

Otra limitación desde el punto de vista de la validez estadística, es que en el caso de las sentencias de los Tribunales de Apelaciones no están cargadas en su totalidad, sino aquellas catalogadas con prioridad media y alta.

Los criterios de prioridad están definidos en varias acordadas del Poder Judicial, entre ellas la acordada 7841, Circular N ${ }^{\circ}$ 75/2015 de la Dirección General de los Servicios Administrativos. 


\section{Análisis de la Jurisprudencia}

\section{A. Frecuencia del delito}

De acuerdo al recorte metodológico adoptado en el período 2000 - 2020 se encontraron 28 sentencias judiciales definitivas referidas a la figura penal del proxenetismo. Como puede observarse en el Cuadro Resumen que se adjunta, la primera de ellas es del año 2004 y la última del año 2019. Los años de mayor frecuencia estadística son 2007 y 2008, con cuatro casos cada uno. En cuanto al Tribunal actuante, las mayores frecuencias se encuentran alojadas en el Tribunal de Apelaciones N. 1 y 2, con 10 casos cada uno.

Si bien el número de sentencias en la Base de Jurisprudencia Nacional ampliado de acuerdo a lo señalado en el capítulo metodológico no es representativo del universo en la medida que solamente se suben las sentencias de alta y media prioridad, sí nos permite un primer acercamiento cuantitativo. Lejos de estar en desuso, el delito de proxenetismo se sigue aplicando al amparo de la Ley 8080 y en un contexto complejo en el que -a diferencia del marco histórico que dio lugar a la Ley- la persecución del proxeneta se debe dar sin afectar las garantías del correcto ejercicio del trabajo sexual regulado por la Ley 17515.

\section{B. Jurisprudencia y Género}

Respecto al sexo de las víctimas en dos casos no se pudo obtener información. De los restantes casos, todos presentan víctimas del sexo femenino y en un solo caso hay presencia de víctimas de ambos sexos, lo que notoriamente demuestra que estamos en presencia de una figura inserta en un sistema que explota fundamentalmente a las mujeres. Algo diferente es la situación en lo referido al sexo de la parte victimaria: si bien la gran mayoría de los casos corresponde al sexo masculino (19), también hay cuatro casos en el que la figura del proxeneta recae en una mujer y otros tres casos en los que la ley de combate al proxenetismo se aplica a personas de ambos sexos. Esta información que contrasta víctimas y victimarios según sexo parece apoyar aquellas voces que describen al sistema prostitucional como inserto en estructuras patriarcalistas (Díez, 2009; Vicente, 2009; Ulloa, 2011; Guerra, 2021).

\section{Delitos conexos}

De la información recogida surge que en el 55\% de los casos, el delito de proxenetismo se aplica en conjunto con otras figuras penales, siendo el caso más notorio el delito de Trata de Personas, Lavado de Activos, Asociación para Delinquir, Suministro de Estupefacientes y explotación sexual a menores de edad. También se aplican en algunos casos otros delitos como hurto, lesiones, homicidio en grado de tentativa, etc.

Como se dijo antes, históricamente el proxenetismo fue asociado a otros delitos conexos, siendo los casos más emblemáticos el delito de Trata (recuérdese la figura de reclutamiento según la Ley 8080) y explotación de menores (es de destacar que la primera tipificación del delito de proxenetismo tiene lugar en el Código Penal de 1889 bajo el capítulo de "corrupción de menores"). También hay evidencia que el mercado prostitucional está muy asociado al consumo de drogas y por esa vía a delitos como 
el suministro de estupefacientes (Goldstein, 1979; Meneses, 2010; Fundación Atenea, 2012) o a la asociación para delinquir (Ochoa, 2017), algo que sobre todo tiene lugar en contextos también de Trata de Personas.

Por lo tanto, una puerta de entrada a la penalización de proxenetismo es mediante la persecución de otros delitos. A manera de ejemplo, en el Caso 3, el imputado llega a la sede judicial para responder por delitos de comercialización de estupefacientes en el prostíbulo que dirigía y fue en el abordaje del caso que emerge el delito de proxenetismo.

Menos usual es por lo tanto que se inicien reclamos y prosperen sentencias sobre proxenetismo cuando no operan otros delitos. ¿Razones? Una primera respuesta podría ser la dificultad específica de este tipo de delitos desde el punto de vista de su investigación y persecución, por ejemplo, en materia de recabar las pruebas y testimonios. Más allá de ese aspecto que ha sido invariable en la historia del Uruguay moderno, creemos que hay un segundo componente más coyuntural relacionado al escenario que surge tras la aprobación de la Ley 17515. En efecto, compatibilizar la persecución del proxenetismo de acuerdo a la redacción dada en 1927 (que como vimos en lo sustancial no cambia con las modificaciones posteriores de 1995) con la plena legalidad del trabajo sexual, no parece tarea sencilla. Si bien es claro que la Ley 17515 solamente permite la prostitución autónoma, en los hechos ha prosperado un mercado de la prostitución, sobre todo en locales como whiskerías y casa de masajes, en los que notoriamente existen terceros que por vía de porcentajes en tarifas y demás condiciones, asoman como explotando la prostitución en cualquier forma y con ánimo de lucro ${ }^{7}$. ¿Se ha aplicado toda la fuerza de la Ley en esos casos? Más bien parece que solamente en una minoría ${ }^{8}$ si nos atenemos a la tesitura que en estos locales se está atentando contra la prostitución autónoma y alentando el proxenetismo. A manera de ejemplo, la activista por los derechos de las trabajadoras sexuales, Karina Núñez ha señalado que "Whiskerías y Casas de Masajes son negocios cooptados por los proxenetas" (en Redacción, 2020). Tuana, de la ONG El Paso por su parte, ha expresado que los locales que ofrecen servicios sexuales:

funcionan como si fuesen empresas autónomas que no tienen nada que ver con las trabajadoras sexuales pero en realidad sus dueños son empresarios que las explotan y se manejan como los dueños de sus vidas (Redacción, 2020).

Es en esas circunstancias complejas que debe actuar el operador judicial y la investigación policíaca, intentando desentrañar en definitiva si existe o no explotación, si hubo o no ánimo de lucro. Como veremos en el próximo apartado, algunas sentencias son especialmente nítidas en lo que refiere a configurar como proxenetismo ciertas conductas por parte de los propietarios/as de locales donde se ejerce la prostitución. Otras, mientras tanto, han operado más en el terreno clásico del proxenetismo callejero en el que se observan otras manifestaciones de la explotación y el lucro.

7 Es así que en 2018 el Tribunal de Apelaciones del Trabajo de 1er Turno, confirmaría la relación laboral entre una trabajadora sexual y sus empleadores.

8 Nótese que la defensa de los inculpados en el Caso 27, en el recurso de Casación (ver Caso 28) expresaría que "si obtener una ganancia derivada del trabajo sexual es un delito, todos los titulares de whiskerías deberían ser condenados" y "no quedaría ninguna whiskería al amparo de la Ley". 


\section{Condenas y agravantes}

Surge de las Sentencias analizadas un total de 41 personas condenadas por proxenetismo. La moda estadística de las condenas es de 4 años y seis meses, aunque con una importante varianza que va desde penas de 10 meses de prisión (aplicadas para coautorías) hasta un máximo de 7 años y 8 meses de penitenciaría en un caso en el que además de proxenetismo se sumó delito de Trata de Personas y Lavado de dinero.

En cuanto a los agravantes, en el 60\% de los casos analizados se aplicaron algunas de las figuras presentes en el Art. 2 de la Ley 8080. La principal figura agravante fue la de "vida marital", seguida de víctima menor a los 18 años de edad. También hubo casos donde se aplicaron como agravantes condición de funcionario policial, así como medios violentos o de coacción.

\section{E. Ámbito de aplicación}

Si bien la figura tradicional del "cafiolo" en nuestras tierras está representado por ese sujeto que domina a sus víctimas a tiempo completo y les controla en las calles, lo cierto es que las actuales modalidades de proxenetismo también operan en locales, caso de prostíbulos, whiskerías y casas de masajes; y asume nuevos formatos como es el caso de los dueños de establecimientos que lucran por medio de los dispositivos ya señalados.

Tomando como referencia el ámbito en el que se ejerció esa explotación con ánimo de lucro, tenemos que la calle y los locales comparten el mismo número de frecuencia en la Base estudiada. También hubo cuatro casos donde el ejercicio prostitucional se materializó en el exterior del país y un caso en el que se hizo mediado por sitios alojados en la web. Por lo visto, hay una tendencia en los últimos años de mayor pasaje de la calle a los locales como ámbito de desempeño del proxenetismo.

\section{F. Componentes e interpretación de la existencia de proxenetismo}

En relación a los tipos más habituales de proxenetismo, de acuerdo a la jurisprudencia analizada emergen cuatro expresiones fundamentales. La primera de ellas pone el acento en conductas de inducción, engaños, uso de violencia, amenazas, abusos de poder o algún otro medio de coacción, operando en el medio local, fundamentalmente prostitución callejera. La segunda expresión está asociada al reclutamiento para el ejercicio de la prostitución fuera de fronteras lo que también implica trata de personas con fines de explotación sexual. En algunos casos suele estar acompañada de tareas de convencimiento o de engaño en la fase de reclutamiento y luego por tareas de control, amenazas y uso de violencia aprovechando la vulnerabilidad de las víctimas cuando se encuentran aisladas, incomunicadas y en territorios desconocidos. Una tercera expresión es cuando opera fundamentalmente tareas de intermediación entre oferta y demanda. El proxeneta en este caso suele contar con una cartera de clientes y con un listado de trabajadoras/as sexuales, siendo su función justamente acercar las demandas de servicio del cliente con la oferta más adecuada. Para ello, obtiene como ganancia un porcentaje del precio pactado. Finalmente tenemos una cuarta expresión, en este caso caracterizada por una explotación más velada por medio de acuerdos comerciales que impactan en la debida autonomía del trabajo sexual. Este tercer tipo de proxenetismo suele expresarse con mayor énfasis en propietarios o gestores de locales (prostíbulos, burdeles, whiskerías, 
casa de masajes) que imponen tarifas, horarios, jornadas y otras normas de trabajo como si se tratara de una relación subordinada de trabajo. Veamos a continuación con más detenimiento estas cuatro formas de proxenetismo.

(1) Por un lado tenemos un conjunto de sentencias que deducen la existencia de explotación por medio de algunos indicadores más convencionales en la materia, típicos del abordaje clásico de aquel proxeneta que controla y domina las vidas de sus mujeres, quienes le proveen de ingresos económicos. Suele presentarse en este tipo de proxenetismo un importante componente de violencia y sometimiento. Observemos algunos ejemplos:

Caso 2: el imputado convenció y luego obligó a dos mujeres (23 y 15 años de edad) a prostituirse en el Parque Roosevelt. Les fijaba el horario y las tarifas, les controlaba en su trabajo y se quedaba con su recaudación.

Caso 3: el imputado obligaba a su mujer a prostituirse en las calles. La controlaba revisando los preservativos. Se quedaba con el dinero. La violentaba y amenazaba.

Caso 5: Una menor de edad es cobijada por dos varones en su vivienda y luego le exigen que pague el hospedaje prostituyéndose. La acompañan a la calle y le vigilan, obligándole a prostituirse. Luego se quedan con sus ingresos que gastan en provecho propio.

Caso 6: Mediante amenazas y violencia, el imputado obligaba a su esposa a prostituirse.

Caso 7: El imputado obliga a su mujer a prostituirse. Le controla y ejerce violencia. Se apropia de sus ingresos.

Caso 8: El imputado obligaba a su esposa e hijas a prostituirse bajo amenazas y ejercicio de la violencia. Se apropiaba de los ingresos obtenidos.

Caso 9: El imputado obliga a su concubina a prostituirse, controlándole y apropiándose de sus ingresos. Se muda con ella y sus hijos al fondo del prostíbulo para asegurar mayores ganancias. Le violentaba y amenazaba,

Caso 10: El imputado indujo a la prostitución a su pareja, una joven con deficiencias mentales, abusando de tal situación para que generara ingresos por ese medio que luego se apropiaba.

Caso 12: el imputado inducía a la prostitución a menores de edad en situación de vulnerabilidad, aprovechándose de los ingresos por ellas obtenidos.

Caso 15: el imputado inducía a varias jóvenes a la prostitución y les controlaba, viviendo de sus ingresos.

Caso 16: el imputado indujo a una joven a la prostitución. Le controlaba y se apropiaba de sus ingresos. Cuando se separaron le amenazaba si no le pagaba por el uso de la parada.

Caso 20: El imputado mediante amenazas y violencia obligó a su novia a prostituirse en la calle desde la edad de 15 años. A los 18 años la hizo trabajar en prostíbulos, quedándose con sus ingresos económicos.

Caso 24: El imputado hacía trabajar a dos mujeres en burdeles, obligándoles bajo amenazas a entregarle el dinero ganado, imponiéndoles pautas de trabajo y controlándoles. 
Caso 25: Los imputados reclutaban jóvenes mujeres a quienes seducían. A los pocos días eran enviadas a trabajar en las calles: "Si no hacíamos plata, nos cagaba a palos" señala una de las víctimas. También eran enviadas a prostíbulos quedándose con la mitad de lo recaudado.

(2) Por otra parte tenemos aquellas expresiones de proxenetismo que se asocian a modalidades de Trata de Personas con fines de explotación sexual fuera del país. Predomina en este tipo, conductas de reclutamiento, convencimiento o engaño en la etapa preparativa, así como conductas de control, amenazas y fuerte explotación laboral en la fase de prostitución fuera de fronteras. De las sentencias analizadas forman parte de esta expresión:

Caso 17: Un matrimonio reclutaba mujeres en Uruguay para enviarlas a Valencia y otras ciudades de España, encargándose de toda la logística para lo cual luego explotaba a las víctimas cobrando importantes porcentajes de sus ingresos. También se dedicaban a traficar drogas.

Caso 21: Los imputados se asociaban para reclutar jóvenes para el ejercicio prostitucional en Italia. La oferta que recibían era la de trabajar en hoteles y cobrar 100 dólares por noche. Sin embargo, las condiciones cambiaban notoriamente al llegar a Italia, donde eran obligadas a ejercer el meretricio en las calles y sin posibilidad de manejar el dinero ganado. Hubo presencia de amenazas y uso de violencia.

Caso 25: Los dos hermanos líderes de la Red de Trata y Proxenetismo enviaban a las víctimas a España, donde le esperaba la madama, quien era encargada de controlarlas y asegurar el envío semanal de dinero. Apenas conservaban lo mínimo para vivir diariamente a pesar que se les había prometido quedarse con la mitad de lo recaudado.

Caso 26. Uno de los imputados, dueño de una empresa de modelaje, organizaba eventos en Buenos Aires donde enviaba a las modelos para mantener relaciones sexuales con sus clientes. En algunos casos hubo engaños para asegurar el viaje de las víctimas.

3) Proxenetismo de intermediación. Como se dijo, la principal característica es que se interviene en el negocio sexual acercando la oferta con la demanda y cobrando un porcentaje por ello. En algunos casos puede implicar conductas típicas de Trata de Personas con fines de explotación sexual en cuanto se favorece la captación, traslado, transporte o acogida de esas personas. Forman parte de este tipo las siguientes Sentencias analizadas:

Caso 18: La imputada reclutaba jóvenes mujeres para enviar al interior del país (Tacuarembó), previo arreglo económico y de detalles del servicio con los clientes, cobrando un porcentaje por ello.

Caso 19: La imputada ofrecía servicios sexuales de trabajadoras y trabajadores sexuales por medio de una página web y luego del contacto del cliente realizaba los arreglos comerciales acercando a las partes. Cobraba por ello el 50\% de la tarifa acordada.

Caso 25: Imputado A publicaba avisos en la prensa para reclutar trabajadoras sexuales a las que luego conectaba con clientes de su cartera. Por tal servicio se embolsaba el $50 \%$ del precio pactado. Imputado B utilizaba una empresa de modelos para reclutar jóvenes $\mathrm{y}$ ofrecer en desfiles como trabajadoras sexuales, implicando engaño o condicionantes para escalar en la carrera de modelaje. 
(4) Finalmente tenemos aquellos casos que vinculan al proxenetismo con la tarea de dirigir un local (prostíbulo, en sus diversas expresiones) en los que se observa algunas de las siguientes acciones: control del trabajo, establecimiento de normas (horarios, tarifas), retención del dinero, aplicación de descuentos en el dinero recibido, etc. No se trata entonces de una figura de proxenetismo con notorias expresiones de abuso y violencia (como en los casos anteriores) sino fundamentalmente de explotación económica, para lo cuál las Sentencias muestran diversos criterios de evaluación que intentan demostrar un cierto abuso en el lucro obtenido. Los casos que encajan con esta modalidad de proxenetismo velado, son los siguientes:

Caso 1: La imputada obtenía un lucro por venta de bebidas, por cobro de tarifas a las trabajadoras sexuales e incluso por abandonar el local con clientes.

Caso 11: El imputado recibía ganancias no solamente por la venta de bebidas, sino además por el cobro de tarifas a las trabajadoras sexuales. Se señala que esas tarifas por uso de habitación, exceden el costo de recambio de las sábanas, como pretendió justificar el encausado. Por lo demás, el imputado era quien establecía las tarifas que debían cobrar las trabajadoras. El Juez alega que ese dinero que cobraba el imputado (aproximadamente $15 \%$ del valor que cobraba la trabajadora) no era para pagar costos, sino una ganancia, que aunque aparentemente pequeña, en una suma total aparecía como una "abusiva contribución".

Caso 27 y 28: El imputado A propietario de dos whiskerías en el interior del país, junto a $\mathrm{B}$ y $\mathrm{C}$, encargados de las mismas, reunían a más de 30 trabajadoras sexuales, la mayoría provenientes de República Dominicana. Éstas, luego de desembarcar en territorio nacional iban directamente a sus locales, donde eran informadas de las condiciones de trabajo: tarifas, horarios, jornadas de trabajo, etc. Se les retenía el porcentaje por copas y servicios sexuales, y además se les cobraba el tiempo en el que mantenían relaciones sexuales fuera del local.

Estos dos casos, que en realidad refieren a una sola investigación, son especialmente relevantes pues luego de la resolución del Tribunal de Apelaciones llega por recurso de Casación a la Suprema Corte de Justicia. La sentencia definitiva de la SCJ por su lado, tiene 19 páginas en las que resume la actual visión respecto a esta particular modalidad de proxenetismo. Detengámonos por lo tanto en sus contenidos.

Analicemos en primer lugar lo resuelto en el Tribunal de Apelaciones. Allí, la defensa de los imputados intenta demostrar que en el país la prostitución es legal, al igual que las whiskerías. Y que es lógico que los propietarios de esos locales reciban un lucro por su actividad, como sucede con cualquier otro empresario. El Tribunal, sin embargo, determina que el imputado AA obtenía ganancias de la prostitución, más allá de que las mujeres con las que contaba se mostraran de acuerdo con el sistema de trabajo:

eran fruto del ejercicio de la prostitución y no como indica la Defensa, que las mismas provinieran de la venta de copas y que lo que aportaban las mujeres fuera sólo para gastos de mantenimiento de las estructuras de los locales.

Indudablemente iba mucho más allá de ello, fijaba las tarifas, cobraba, quedaba con el dinero de las mujeres en depósito, las ubicaba en eventos fuera del local, por supuesto que además se ocupaba de que consiguieran documentación y se cuidaran y controlaran la salud. Ninguna de ellas dice que fueran maltratadas física o psicológicamente. 
AA tenía en la actividad un afán de lucro con base directa en el trabajo de las mujeres que prestaron su consentimiento para ello, lo que no enerva la tipificación (Caso 27).

La sentencia es clara en señalar que "en nuestro país la prostitución no es delito y quien trabaja o explota una whisquería, por ese sólo hecho, no es proxeneta", pero también es enfática en aplicar la Ley 8080 debido a la evidencia que establecía la retención de lo recaudado aplicando descuentos de manera de asegurarse las ganancias, así como otras conductas caso de cobrar por el tiempo que pasaban fuera del local.

Llegado a la Suprema Corte de Justicia (recurso de casación interpuesto por dos de los cinco imputados), se sostiene esta tesitura al señalarse que

No resulta de recibo el argumento del recurrente, que sostuvo que su actividad se circunscribiera a la explotación de la whiskería, cobrando apenas por la ocupación de las piezas y un porcentaje de las copas (Caso 28).

\section{Continúa la SCJ:}

El planteo de la supuesta actividad comercial lícita se desvanece. No se trataba del cobro por un servicio como el de ocupación de una habitación, sino de una explotación (abusiva) de la prostitución para obtener parte de los ingresos de las meretrices, conforme lo requerido por la ley (Caso 28).

El abuso vendría del hecho de fijar tarifas, cobrar, retener el dinero, aplicarle descuentos, o incluso lucrar por sus trabajos fuera del local. Por lo tanto

El accionar de AA no es el de un mero comerciante, titular de una whiskería que cobra un dinero por la ocupación de las habitaciones empleadas para la prestación de los servicios sexuales. Se trata de alguien que dominó completamente la forma de trabajo de las meretrices... (Caso 28).

Una manera de sostener esta interpretación es recurriendo a anterior jurisprudencia. En tal sentido, establece el Dictamen, que a conclusiones similares arriba la Sentencia No. 185/2015, del Tribunal de Apelaciones en lo Penal de 1er. Turno (caso 10 en nuestro listado):

Parece claro que si el dueño o responsable de una Whiskería quiere quedar fuera del reproche, debe abstenerse -por completo- de percibir cualquier retribución por los servicios que prestan las prostitutas que allí se desempeñan... (Caso 28)

La SCJ también cita al Tribunal de Apelaciones en lo Penal de 3er. Turno (sentencia 340/04, que figura como Caso 1 en nuestro listado):

... Z.N. debe ser considerada autora penalmente responsable de un delito de proxenetismo ya que con ánimo de lucro se dedicó a explotar la prostitución de varias meretrices que trabajaban en una finca por ella arrendada, la que era utilizada como 
lugar de encuentros sexuales entre los clientes y las meretrices las cuales debían hacerle aportes varios (si se retiraban de la finca con un cliente \$100), lograr que el cliente pagara una copa siendo la mitad del precio para la encausada y además una comisión de $\$ 50$ cada vez que se ocupaban en la finca, siendo la encausada la que establecía las tarifas (Caso 1).

Una tercera cita es la referida al Tribunal de Apelaciones en lo Penal de 2do. Turno No. 452/2006, en la que dicha Sala sostuvo:

...[el imputado] resultó una pieza neurálgica en el funcionamiento de la estructura: él fijaba el precio, la participación del $50 \%$ en las bebidas y comercio sexual y las jóvenes NO PERCIBÍAN SUS INGRESOS SIN QUE RR LO DISPUSIERA todo lo que constituye su directa participación en el delito atribuido: el dolo se manifiesta en la voluntad de explotar la prostitución contribuyendo para ello en cualquier forma y en la conciencia de hacerlo para obtener el lucro, integrando (copas y sexo) una suerte de 'conjunto económico' que compromete la situación penal del encausado; cooperó al ejercicio del meretricio favoreciendo activamente el trato sexual comercial (Caso 28).

Por lo tanto, en estas Sentencias se evidencia esa explotación a la que se refiere la Ley 8080 y ese abuso que se expone en el Art. 34 de la Ley 17515 por medio de los siguientes indicadores:

(i) retención de las ganancias generadas por la trabajadora sexual y posterior descuento de porcentajes;

(II) cobro de porcentajes en otros servicios (ejemplo copas);

(III) establecimiento de condiciones de trabajo que limitan el ejercicio autónomo de la prostitución;

(IV) Control del trabajo realizado.

En resumen, la SCJ reconoce como evidencia de proxenetismo cualquiera de esas acciones llevadas adelante eventualmente por el propietario de un prostíbulo.

Es cierto que, a lo largo de sus 19 páginas, la Sentencia abona el campo de las dudas. Nótese que por un lado cita la Sentencia 182/2015 (caso 11), que categóricamente afirma que la única manera de evitar ser investigado por proxenetismo sería "abstenerse -por completo- de percibir cualquier retribución por los servicios que prestan las prostitutas". Pero por otro lado establece, luego de repasar cierta Doctrina, que "Una contribución y el lucro consiguiente, no abusivos y no excesivos, no constituye proxenetismo". ¿Cuál de las dos expresiones es la correcta? De acuerdo a la primera parecería que no habría margen para el negocio fuera de lo que recibe la trabajadora sexual. De acuerdo a la segunda frase, sin embargo, parecería ser que el meollo del asunto consiste en determinar la diferencia entre una explotación o lucro no abusivo y una explotación o lucro abusivo. Los ejemplos de la Sentencia son imprecisos, ya que como casos hipotéticos de una contribución y lucro no abusivo citan pasajes de diferentes sentencias en las que no está presente la figura del propietario de local que establece las reglas de juego y cobra 
porcentajes por los servicios sexuales, sino otro tipo de actores, sujetos o circunstancias, caso de la Sentencia 196/96 del TAP de 1er turno:

Así, el dueño de una casa de citas, el taxista o el botones de un hotel que gestiona con meretrices a cambio de una propina, si bien en rigor lucran con la prostitución, perciben una retribución normal por el servicio, no 'explotan abusivamente' la prostitución despojando a la mujer que ejerce el comercio carnal de 'la parte del león' de sus honorarios por la prestación del servicio, y consecuentemente no están incursos en la figura del proxenetismo; no conjugan el verbo nuclear del tipo 'explotar' (caso 28).

Sin embargo, más allá de esos ejemplos, la construcción del Fallo se hace fuerte en el razonamiento jurídico de lo que constituye una explotación o lucro abusivo. A los efectos de entenderlo mejor, proponemos analizar tres posibles escenarios:

(a) Un primer escenario hipotético tiene lugar cuando el propietario se abstiene de percibir cualquier ingreso por parte de la trabajadora sexual. En ese caso, parecería claro que no hay lugar a la figura de proxenetismo. También forma parte de este escenario quien solamente alquila las piezas para el encuentro sexual, sin inmiscuirse en el acuerdo privado entre cliente y trabajadora sexual, quien debe manejarse con absoluta autonomía.

(b) Un segundo escenario posible es cuando el propietario admite cobrar no solamente por las piezas, sino además participar de otras ganancias como ser la venta de copas. Justamente este escenario es el que la Defensa de los indagados intentó justificar sin éxito:

No resulta de recibo el argumento del recurrente, que sostuvo que su actividad se circunscribiera a la explotación de la whiskería, cobrando apenas por la ocupación de las piezas y un porcentaje de las copas. Se comprobó que retenía la recaudación diaria de las trabajadoras sexuales y practicaba sobre dichas sumas los descuentos (como si de un agente de retención se tratara), para asegurar sus ganancias. También se probó que les cobraba por el tiempo que pasaban fuera del local atendiendo clientes. Esto último sella la suerte de la tesis de la defensa (caso 28).

(c) Esas conductas comprobadas y no señaladas por la Defensa que colocamos en negrilla, son las que abren la puerta al tercer escenario de explotación abusiva. Nótese que la sola presencia de estas acciones, sin hacer mención a la cuantía (ver nota al pie no. 6), ya configuran para la SCJ caso de abuso:

Como bien lo señaló la Sala, en términos que comparte la Corporación, el recurrente no obtenía una ganancia por la mera venta de copas y el alquiler de las habitaciones empleadas para la prestación de los servicios sexuales. Antes bien: “...iba mucho más allá de ello, fijaba las tarifas, cobraba, quedaba con el dinero de las mujeres en depósito, las ubicaba en eventos fuera del local, por supuesto que además se ocupaba que consiguieran documentación y se cuidaran y controlaran la salud"(Caso 28). 
Por lo tanto, este tercer escenario de explotación abusiva implica todas esas acciones antes mencionadas que refieren a un total dominio de las formas de trabajo: fijar tarifas, cobrar, quedarse con el dinero en depósito e incluso ubicarlas en eventos fuera del local, además de otras también explicitadas, caso de impedirles "el ejercicio libre del meretricio fuera de sus locales, desde que debían abonarle una tarifa de $\$ 70^{\prime \prime}$.

De esta manera, los locales habilitados para el ejercicio de la prostitución no deberían incurrir en ninguna de estas acciones propias del tercer escenario para no caer bajo esta cuarta y más velada forma de proxenetismo.

\section{Conclusiones}

En el presente trabajo hemos analizado la información que surge de las 26 sentencias que figuran en la Base de Jurisprudencia del Poder Judicial ampliadas por técnica de bola de nieve a un total de 28 sentencias definitivas respecto a la aplicación del delito de proxenetismo que resulta de la Ley 8080 y las modificaciones posteriores de 1995 (Ley 16707).

Hemos observado cómo desde 2002 con la aplicación de la Ley 17515, el ejercicio de la prostitución es legal, sin embargo, se continúa castigando toda explotación de otra persona, sea cual sea la forma en que se contribuya a ello, siempre que exista el ánimo de lucro y aún en el caso que hubiera mediado consentimiento de la víctima.

Creemos que el escenario actual donde justamente intervienen ambas leyes, una regulando el ejercicio del meretricio, otra persiguiendo el lenocinio, complejiza la persecución del delito, sobre todo en la variante que hemos denominado "proxenetismo velado" (tipo 4 en nuestra clasificación) en el sentido de una modalidad que esconde la explotación bajo el velo de una actividad empresarial mediante la cuál se explota a la víctima fundamentalmente desde un punto de vista económico, como si se tratara de cualquiera otra actividad empresarial.

La Jurisprudencia muestra un cierto avance en los últimos años, respecto al reconocimiento de aquellos indicadores de explotación como sinónimo de una ganancia o lucro abusivo. En resumen, se entiende que el propietario de un prostíbulo o similar que se inmiscuya o participe fijando normas que afecten el tiempo, las características o las tarifas del trabajo sexual, estaría superando el umbral de la licitud establecida por la Ley 17515 y por lo tanto incurriendo en el delito tipificado por la Ley 8080. Así se han expresado en el período 2000 - 2020, cuatro casos analizados, incluyendo una Sentencia de casación de la Suprema Corte de Justicia firmado el 29 de agosto de 2019.

Retomando las preguntas disparadoras de la investigación podemos concluir lo siguiente:

a) El delito de proxenetismo está plenamente vigente y aunque en una alta proporción se investiga cuando se disparan otros delitos, fundamentalmente caso de la Trata de Personas (Ley 19463) o Explotación Sexual (Ley 17815), también hay varias sentencias en las que se aplica únicamente la Ley 8080. 
b) La Ley es aplicada para cada uno de los cuatro tipos analizados en este artículo, incluido el tipo más complejo, esto es, lo que hemos denominado un "proxenetismo velado".

c) La regulación del trabajo sexual no es determinante para dejar de perseguir el delito de proxenetismo pues la Legislación vigente es clara en diferenciar el trabajo sexual autónomo de acuerdo a lo señalado en la Ley 17515 y aquellos casos en los que se configura el delito de proxenetismo. Aún así -y como se dijo antes- el desarrollo del mercado del sexo fue montando locales en los que esa autonomía da paso a una relación informal de subordinación que ha implicado interpretar detenidamente la existencia o no de abuso en la explotación por parte de un tercero.

\section{Referencias bibliográficas}

Abadie Santos, H. (1932). Represión del Proxenetismo, Montevideo, Impresora Moderna.

Albanell Mc Coll, E. (1932) Legislación sobre proxenetismo y delitos afines, Montevideo, Universidad de la República.

Bayardo Bengoa, F. (1957). Sobre delitos sexuales, Montevideo, CED.

Cairoli, M. (1989). Curso de Derecho Penal Uruguayo Tomo III, Montevideo, FCU.

Fessler, D. (2012). Derecho Penal y Castigo en el Uruguay (1878 - 1907), Montevideo, CSIC, Biblioteca Plural.

Fleitas, S. (2014). Delitos migratorios, Tráfico de Personas y Trata de Personas, Montevideo, FCU.

Fundación Atenea (2012). Pautas y modelos de consumo abusivo de drogas en mujeres que ejercen la prostitución. Madrid: Ministerio de Sanidad, Servicios Sociales e Igualdad

Goldstein, J.P. (1979). Prostitution and Drugs. D.C. Heath and Company. Massachusetts, Toronto. Lexington Books

Guerra, P. (2015). “¿Régimen de Dependencia Laboral en el trabajo sexual? Análisis de la evidencia empírica para el caso uruguayo", Montevideo, Revista de Derecho Laboral Tomo LVIII, N. 259, p. $453-465$.

Guerra, P. (2016). La prostitución en Uruguay. Entre el trabajo y la explotación sexual, Montevideo, CSIC.

Guerra, Pablo (2021). "Sistema prostitucional, patriarcalismo y mercantilismo" (en línea) Revista Hemisferio Izquierdo, Recuperado de https://www.hemisferioizquierdo.uy/single-post/sistema-prostitucional-mercantilismo-y-patriarcalismo

Langón Cuñarro, M. (2010). Código Penal y Leyes Penales complementarias de la República Oriental del Uruguay, Tomo II - De los Delitos en particular. Montevideo. Editorial Universidad de Montevideo.

Meneses, C. (2010). “Usos y abusos de drogas en contextos de prostitución”, Revista Española de Drogodependencias, Vol. 35, N. 3. 
Ochoa, M. (2017). Del crimen organizado al crimen desordenado: una apuesta por la observación conceptual y contextual. Desacatos, (54), 92-105. Recuperado de http:/ / www.scielo.org.mx/scielo.php?script=sci_arttext\&pid=S1607-050X2017000200092 \&lng=es\&tlng=es

Redacción (2020). “Cómo se regula el trabajo sexual en Uruguay y qué puede aportar al debate aergentino" (en línea). Recuperado de https://www.redaccion.com. ar /como-se-regula-el-trabajo-sexual-en-uruguay-y-que-puede-aportar-al-debateargentino/

Ulloa, T. (2011). “La prostitución, una de las expresiones más arcaicas y violentas del patriarcado contra las mujeres" Pensamiento Iberoamericano N. 9, p. $293-311$.

Vicente, S. (2009). "La prostitución también es violencia machista" Critica: La Reflexión Calmada Desenreda Nudos 59 (960):48-52.

\section{Normas citadas}

Código Penal 1889, Montevideo, Imprenta el Siglo Ilustrado.

Código Penal, Cuarta Edición actualizada y comentada, Montevideo, FCU, Marzo de 2019.

Ley 5020 de 1916, Diario Oficial, 21 de Octubre de 1916.

Ley 8080, Delito de Proxenetismo, Diario Oficial, 27 de mayo de 1927.

Decreto del 30 de Mayo de 1928, mimeo.

Ley 17.515 Sobre el Trabajo Sexual, Diario Oficial, 9 de julio de 2002.

Decreto 480/003, Reglamentación sobre Ley de Trabajo Sexual, Diario Oficial, 28 de Noviembre de 2003.

Ley 17815, sobre Violencia Sexual contra niños, adolescentes o Incapaces, 14 de Setiembre de 2004 .

Ley 18.250 sobre Migraciones, Diario Oficial, 17 de enero de 2008.

Ley 19643 sobre Prevención y Combate de la Trata de Personas, Diario Oficial, 14 de Agosto de 2018.

Sentencias Analizadas (ordenadas por año)

TAP 3, No. 340, 2004

TAP 2, No. 104, 2006

TAP 2, No. 228, 2006

TAP 3, No. 205, 2007

TAP 1, No 120, 2007

TAP 1, No. 224, 2007

TAP 1, No. 449, 2007 
TAP 1, No. 104, 2008

TAP 1, No. 191, 2008

TAP 1, No. 392, 2008

TAP 2, No. 09, 2008

TAP 3, No. 26, 2009

TAP 2, No. 121, 2009

TAP 1, No. 69, 2010

TAP 1, No. 114, 2010

TAP 2, No. 365, 2010

TAP 2, No. 474, 2010

TAP 3, No. 35, 2011

TAP 3, No. 64, 2013

TAP 2, No. 283, 2013

TAP 1, No. 211, 2013

TAP 2, No. 137, 2014

TAP 2, No. 380, 2014

TAP 1, No. 182, 2015

TAP 4, No. 374, 2015

Letrado $1^{\text {a }}$, N. 8, 2015

TAP 4, No. 75, 2018

SCJ, No. 1299, 2019 


\section{Anexo:}

\begin{tabular}{|c|c|c|c|c|c|c|c|c|c|c|c|c|}
\hline $\begin{array}{l}\frac{7}{\pi} \\
\frac{\pi}{0} \\
\frac{\pi}{\pi} \\
\frac{0}{\Sigma}\end{array}$ & 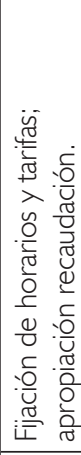 & 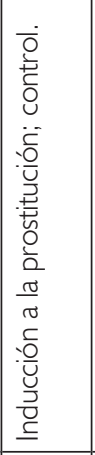 & 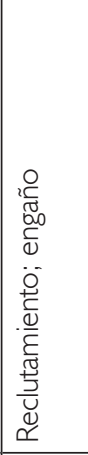 & $\frac{D}{n}$ & 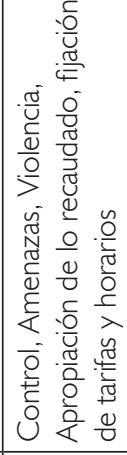 & 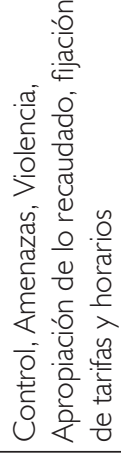 & 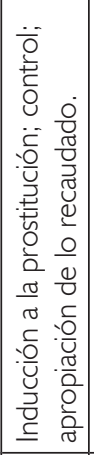 & 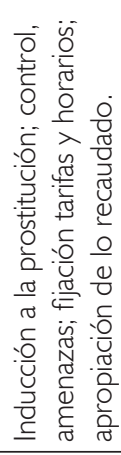 & 要 & 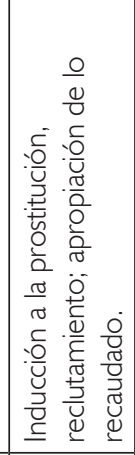 & 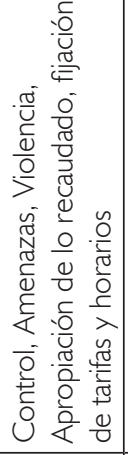 & 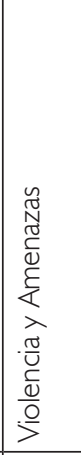 \\
\hline 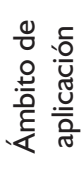 & तु & $\frac{\varrho}{\overline{\widetilde{U}}}$ & $\begin{array}{l}\frac{\overline{0}}{\overline{\frac{0}{\nu}}} \\
\frac{\bar{x}}{4}\end{array}$ & $\frac{D}{n}$ & 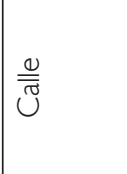 & $\frac{\varrho}{\stackrel{\bar{J}}{\cup}}$ & $\frac{\stackrel{\varrho}{\bar{J}}}{\widetilde{J}}$ & 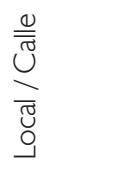 & ত্তু & $\frac{\stackrel{0}{\bar{J}}}{\mathrm{~J}}$ & $\frac{\varrho}{\overline{\widetilde{U}}}$ & ত্তু \\
\hline 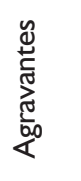 & & 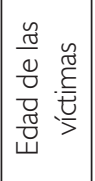 & & 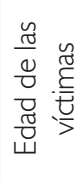 & 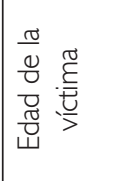 & 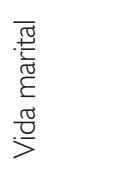 & 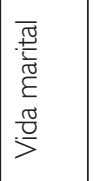 & 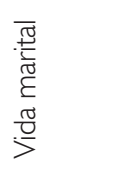 & & & 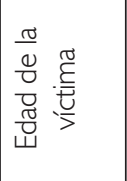 & 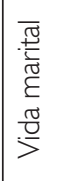 \\
\hline 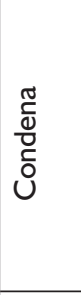 & $\begin{array}{l}\tilde{O} \\
\stackrel{\sim}{0} \\
\sim\end{array}$ & 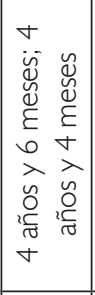 & 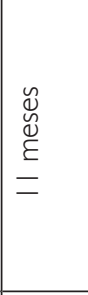 & 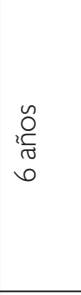 & 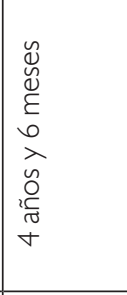 & 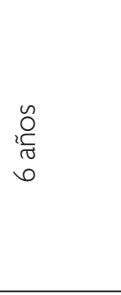 & 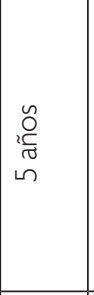 & 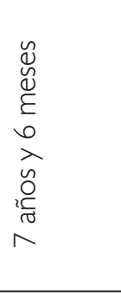 & 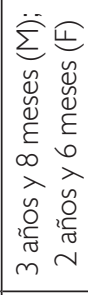 & 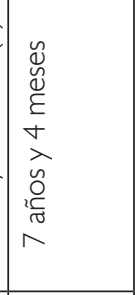 & 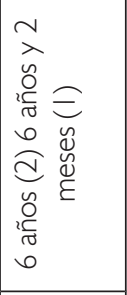 & 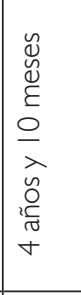 \\
\hline 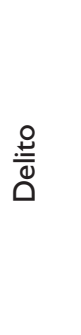 & 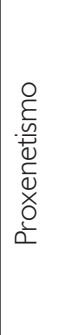 & 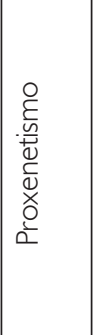 & 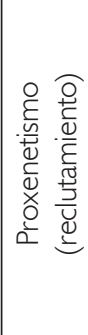 & 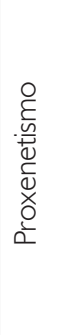 & 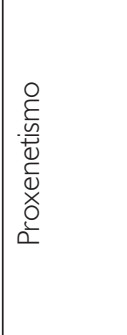 & 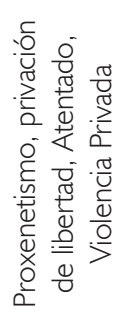 & 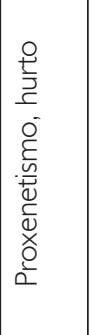 & 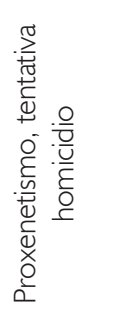 & 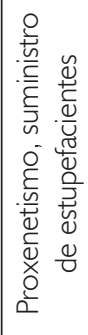 & 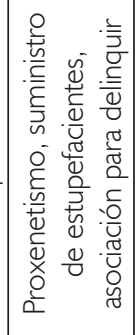 & 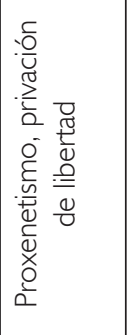 & 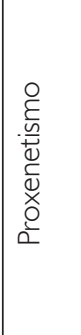 \\
\hline 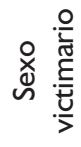 & $\sqcup$ & $\Sigma$ & $\sqcup$ & $\Sigma$ & $\Sigma$ & $\Sigma$ & $\Sigma$ & $\Sigma$ & $\frac{\stackrel{L}{\lambda}}{\Sigma}$ & & 帝 & $\Sigma$ \\
\hline 丞 & $\frac{2}{i n}$ & $\frac{D}{n}$ & $\frac{\pi}{n}$ & $\frac{i}{n}$ & $\begin{array}{l}\stackrel{n}{\lambda} \\
\stackrel{n}{n}\end{array}$ & $\frac{i}{n}$ & $\underline{\infty}$ & $\frac{i}{n}$ & $\frac{D}{n}$ & & $\underline{0}$ & $\frac{D}{n}$ \\
\hline 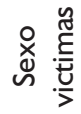 & $\sqcup$ & $\sqcup$ & ப & $\sqcup$ & $\sqcup$ & $\sqcup$ & $\sqcup$ & $\sqcup$ & $\sqcup$ & $\sqcup$ & $\sqcup$ & $\sqcup$ \\
\hline 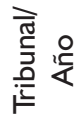 & 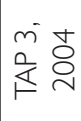 & $\left|\begin{array}{ll}1 & 0 \\
0 & 0 \\
1 & 0 \\
1 & 1\end{array}\right|$ & 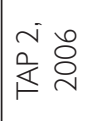 & $\begin{array}{l}m^{-} \\
\text {文客 }\end{array}$ & 定总 & -iô & 定总 & 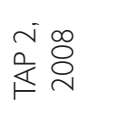 & ì & 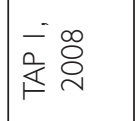 & $\begin{array}{l}\bar{c} \\
\bar{a} \\
\dot{1}\end{array}$ & $\begin{array}{l}m^{-} \\
\stackrel{0}{1} \delta \\
1\end{array}$ \\
\hline
\end{tabular}




\begin{tabular}{|c|c|c|c|c|c|c|c|c|c|c|}
\hline 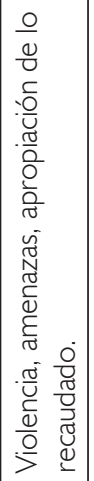 & 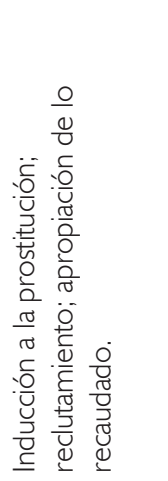 & 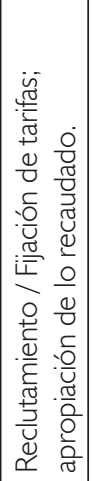 & 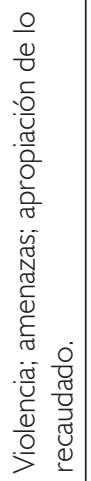 & 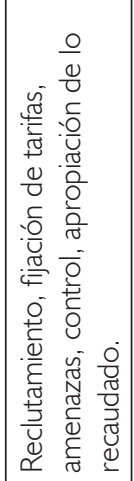 & $\frac{2}{n}$ & $\frac{2}{n}$ & 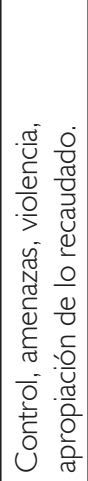 & 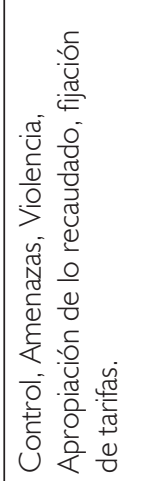 & 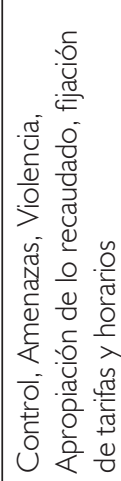 & 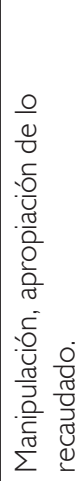 \\
\hline$\frac{\varrho}{\overline{\widetilde{U}}}$ & $\begin{array}{l}\bar{\Phi} \\
\stackrel{0}{1}\end{array}$ & 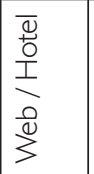 & 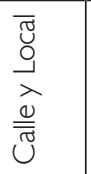 & $\frac{\varrho}{\bar{~}}$ & $\frac{2}{n}$ & $\frac{2}{n}$ & 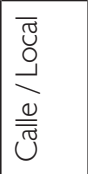 & $\begin{array}{l}\overline{\widetilde{U}} \\
\stackrel{G}{0}\end{array}$ & $\begin{array}{l}\overline{\mathscr{U}} \\
\stackrel{9}{ }\end{array}$ & $\begin{array}{l}\text { तु } \\
\text { ত্ }\end{array}$ \\
\hline $\begin{array}{l}\frac{\pi}{0} \\
\frac{0}{0} \\
\frac{0}{0} \\
\frac{0}{7}\end{array}$ & 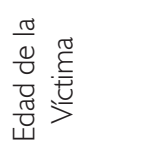 & & & & 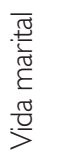 & & & 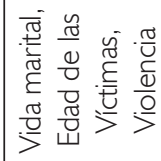 & 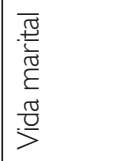 & 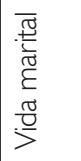 \\
\hline 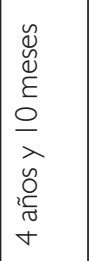 & 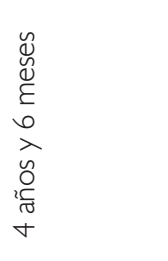 & $\begin{array}{l}\widetilde{0} \\
\substack{\tilde{J} \\
\forall}\end{array}$ & 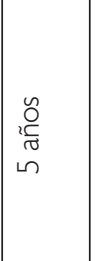 & 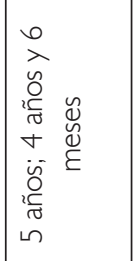 & 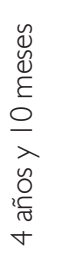 & 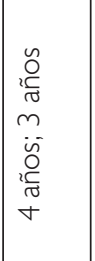 & $\begin{array}{l}\text { ô } \\
\text { in } \\
\text { in }\end{array}$ & 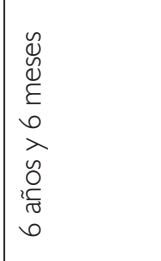 & 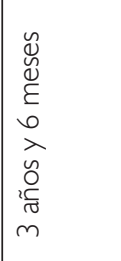 & 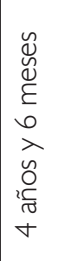 \\
\hline 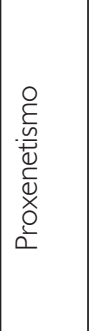 & 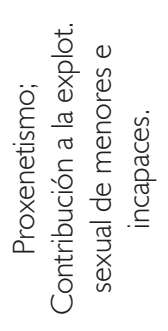 & 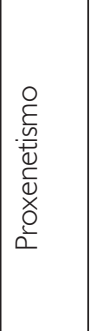 & 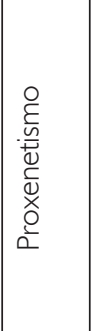 & 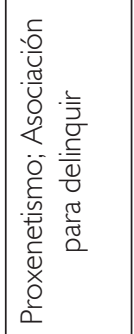 & 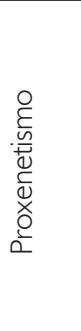 & 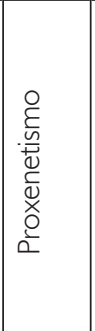 & 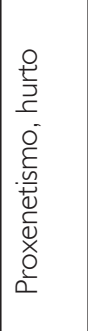 & 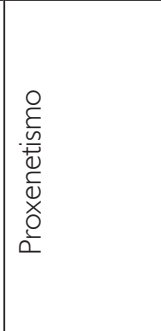 & 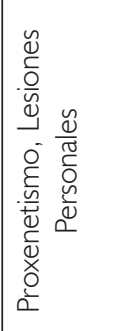 & 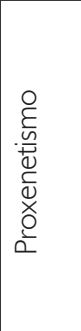 \\
\hline$\Sigma$ & $\sqcup$ & レ & $\Sigma$ & $\Sigma$ & $\Sigma$ & $\Sigma$ & $\Sigma$ & $\Sigma$ & $\Sigma$ & $\Sigma$ \\
\hline$\frac{D}{n}$ & $\stackrel{\bullet}{ }$ & $\frac{D}{n}$ & $\stackrel{\curvearrowright}{\curvearrowright}$ & $\frac{\partial}{n}$ & $\frac{2}{n}$ & $\frac{2}{n}$ & $\frac{2}{n}$ & 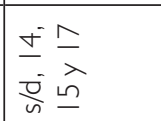 & $\frac{2}{n}$ & $\frac{\partial}{n}$ \\
\hline$\sqcup$ & $\sqcup$ & $\sum_{\downarrow}$ & レ & $\sqcup$ & $\frac{2}{n}$ & $\frac{2}{n}$ & $\sqcup$ & $\sqcup$ & $\sqcup$ & ч \\
\hline 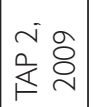 & $\begin{array}{l}\overline{-} \\
\bar{a} \\
\overline{1}\end{array}$ & 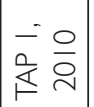 & $\begin{array}{ll}i & 0 \\
\frac{1}{1} & 0 \\
1 & 0\end{array}$ & $\begin{array}{ll}i & 0 \\
\frac{\alpha}{1} & 0 \\
1\end{array}$ & $\begin{array}{l}m^{-} \\
\dot{\alpha} \bar{i}\end{array}$ & $\mid \begin{array}{ll}m & m \\
\frac{1}{2} & \frac{m}{2} \\
1 & 0\end{array}$ & $\frac{m}{\frac{1}{2}}$ & 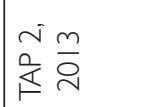 & 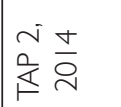 & i \\
\hline
\end{tabular}




\begin{tabular}{|c|c|c|c|c|}
\hline 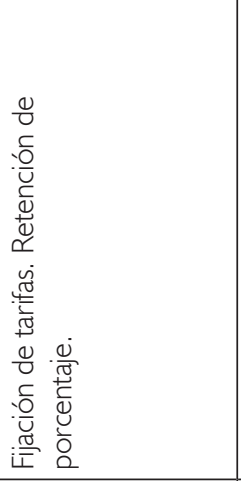 & 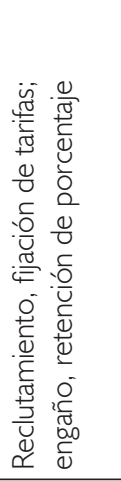 & 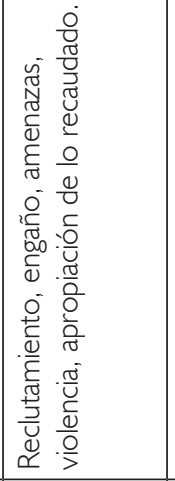 & 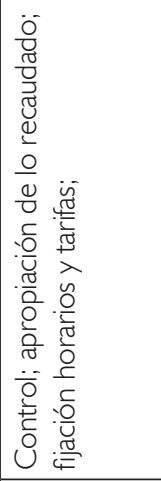 & 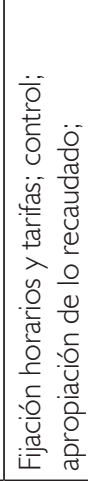 \\
\hline 䓞 & 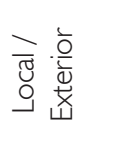 & 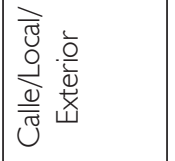 & 정 & 疋 \\
\hline 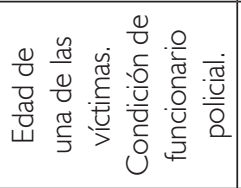 & 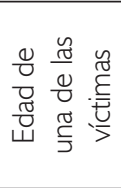 & 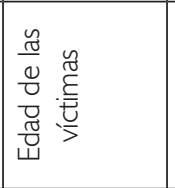 & & \\
\hline 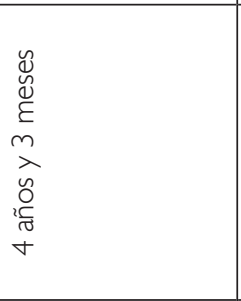 & 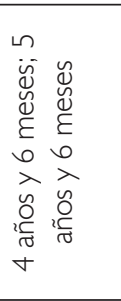 & 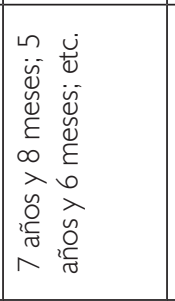 & 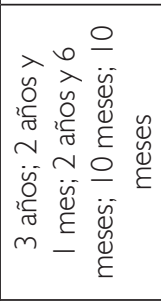 & 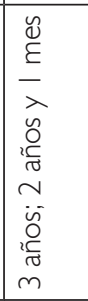 \\
\hline 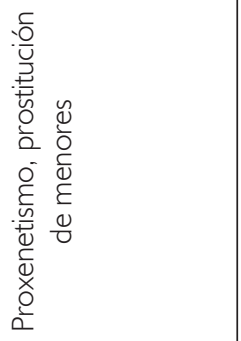 & 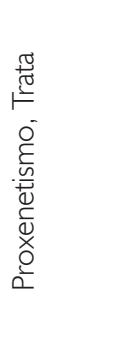 & 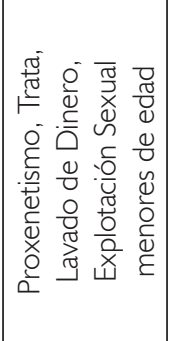 & 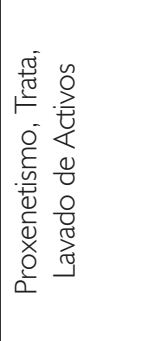 & 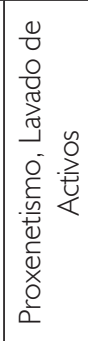 \\
\hline$\Sigma$ & $\Sigma$ & $\Sigma$ & $\stackrel{\stackrel{L}{\lambda}}{\sum^{\lambda}}$ & $\stackrel{\stackrel{\nu}{\lambda}}{\underset{\Sigma}{\Sigma}}$ \\
\hline$\frac{i}{n}$ & $\frac{D}{n}$ & 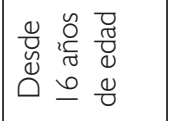 & & $\frac{D}{n}$ \\
\hline$\sqcup$ & $\sqcup$ & $\bullet$ & $\sqcup$ & $\bullet$ \\
\hline 定品 & 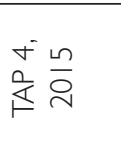 & $\begin{array}{l}\frac{\pi}{0} \\
\frac{0}{0} \\
\frac{0}{0} \\
\end{array}$ & 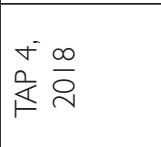 & $\begin{array}{l}\frac{a}{2} \\
\bar{v} \\
\bar{u}\end{array}$ \\
\hline
\end{tabular}

